\title{
VICENTE HUIDOBRO: \\ DEL REINO MECÁNICO AL APOCALIPSIS
}

\author{
POR \\ Óscar Hahn \\ University of Iowa
}

Desde sus inicios creacionistas, el pensamiento literario de Huidobro se fue moviendo entre dos polos: el Génesis y el Apocalipsis; la gestación de un mundo mediante la palabra y la postrera aniquilación de ese mundo. "La poesía - dice Huidobro- está antes del principio del hombre y después del fin del hombre. Ella es el lenguaje del Paraíso y el lenguaje del Juicio Final" (716).'

"Ecuatorial" se abre en uno de sus extremos con un discurso adánico, fundacional: "Era el tiempo en que se abrieron mis párpados sin alas / y empecé a cantar sobre las lejanías desatadas", y se cierra en el otro con los sones del "clarín aun fresco que anuncia / el Fin del Universo". Algo semejante, aunque a otro nivel, sucede en Altazor. El poema se inaugura en el "Prefacio" con el nacimiento del héroe y de su entorno recién creado: "Nací a los 33 años el día de la muerte de Cristo", y culmina en el Canto VII con el colapso de Altazor y el estallido del mundo verbal que lo circunda.

$\mathrm{El}$ aspecto "adánico", al que ya me he referido en mi artículo "Vicente Huidobro o la voluntad inaugural", puede ilustrarse con el simple expediente de recurrir al núcleo de la teoria creacionista, sintetizada en esta declaración suya: "La poesía es el vocablo virgen de todo prejuicio; el verbo creado y creador, la palabra recién nacida. Ella se desarrolla en el alba primera del mundo" (716).

Como contrapartida, Temblor de cielo contiene una de las visiones más apocalípticas que existen en la poesía de Huidobro:

Al mismo instante hubo en el cielo un espantoso terremoto. Se rompian las estrellas en mil pedazos, se incendiaban los planetas, volaban trozos de lunas, saltaban carbones encendidos de los volcanes de otros astros y venían a veces a clavarse chirriando en los ojos desorbitados de los hombres. La muchedumbre huía despavorida. Unos se escondían pidiendo auxilio bajo la tierra, otros caían de rodillas golpeándose el pecho y clamando perdón con los brazos levantados al firmamento (446).

\footnotetext{
${ }^{1}$ Las citas de Huidobro, tanto en prosa como en verso, provienen de: Obras completas de Vicente Huidobro I, prólogo de Hugo Montes (Santiago: Andrés Bello, 1976). Sólo las citas de la novela La próxima proceden del tomo II. Indico las páginas en medio de paréntesis.
} 
¿Cuál es el proceso que conduce del alba del mundo a su hecatombe final; del Génesis al Apocalipsis? En primer término, es preciso puntualizar que, para Huidobro, crear significa hacerlo contra la Naturaleza, que ha sido creada por Dios: "El poeta no imitará más a la naturaleza, pues no se da el derecho de plagiar a Dios", dice (763). El manifiesto "Non serviam" es todo un ataque contra la Naturaleza y una convocatoria a liberarse de su yugo: "El poeta, en plena conciencia de su pasado y de su futuro, lanzaba al mundo su declaración de independencia frente a la Naturaleza. Ya no quiere servirla más en calidad de esclavo" (716).

El fundamento de esta estética es aquello que Gaston Bachelard llama "el espíritu científico". Dice Bachelard: "El espíritu científico debe formarse en contra de la Naturaleza; en contra de lo que es, dentro y fuera de nosotros, impulso y enseñanza de la Naturaleza, en contra del entusiasmo natural, en contra del hecho coloreado y vario. El espíritu científico debe formarse reformándose. Frente a la Naturaleza sólo puede instruirse purificando las sustancias naturales y ordenando los fenómenos revueltos". ${ }^{2}$ La Naturaleza, como obstáculo epistemológico, es omnipresente en los textos de Huidobro. Basta recordar ese momento de la novela La próxima en que el narrador advierte alarmado que "la naturaleza no cederá fácilmente el campo" (317).

En Europa, la ruptura rotunda con la Naturaleza sólo se produce con el Futurismo y con el Cubismo. Y aunque Cézanne es considerado un precursor de este último movimiento, puede decirse que lo es sólo parcialmente. En su carta a Émile Bernard, Cézanne ya habla de esferas, conos y cilindros; pero, en rigor, no los propone como objetos que se agregan a la realidad, sino como modelos para obtener nuevas visiones del mundo natural.

Donde empezamos a vislumbrar la base misma del pensamiento de Huidobro es en el manifiesto "La creación pura". Lo que Huidobro hace es analogar la poesía creacionista a la Mecánica (o a la tecnología, diríamos ahora), cuando reclamando contra los científicos que niegan al artista el derecho de creación, pregunta: “¿Acaso el arte de la mecánica no consiste también en humanizar a la Naturaleza y no desemboca en la creación”. En seguida viene el elogio de varios productos de la tecnología que sustituyen a nuestros órganos sensoriales o a funciones del cerebro: "El hombre empieza por ver, luego oye, después habla y por último piensa. En sus creaciones, el hombre siguió este mismo orden que le ha sido impuesto. Primero inventó la fotografia, que consiste en un nervio óptico mecánico. Luego el teléfono, que es un nervio auditivo mecánico. Después el gramófono, que consiste en cuerdas vocales mecánicas; $y$, por último el cine, que es el pensamiento mecánico" (661). Esas máquinas, igual que la poesía creacionista, son para Huidobro construcciones artificiales; orgullosas invenciones del hombre que se suman al repertorio producido por el mundo natural, para competir con él y superarlo.

En el fondo, lo que Huidobro está planteando es que la poesía creacionista es una especie de máquina verbal: un arte-facto que funciona según leyes que el poeta inventa. De este modo queda establecida, de manera más rotunda que en "Non serviam", la oposición entre las creaciones de la Naturaleza y las creaciones de la Mecánica; 0 , más específicamente, la oposición entre lo Natural y lo Artificial. "Lo realizado en la mecánica también se ha hecho en la poesía", dice Huidobro (733).

\footnotetext{
${ }^{2}$ Gaston Bachelard, El espiritu cientifico (Buenos Aires: Siglo XXI, 1974) 27.
} 
Es aquí donde quedan de relieve las pretensiones cientificistas de Huidobro y su deseo de que la teoría y la poesía creacionistas se integren al ámbito de la ciencia; pretensiones que por lo demás ya se explicitaban en el "Prefacio" del poema Adán, cuando señalaba: "Muchas veces he pensado escribir una Estética del Futuro, del tiempo no muy lejano en que el Arte esté hermanado, unificado con la Ciencia" (223). Y aunque al final del "Prefacio" cita con elogio al filósofo norteamericano Ralph Waldo Emerson, y en particular la idea de que el poema debe tener una "arquitectura propia" y adornar la Naturaleza con una cosa nueva, como una planta o un animal, se lamenta de que "este hombre admirable no hubiera sido más científico" (26). Tal "Estética del Futuro" es "La creación pura". ${ }^{3}$

Después de explicar detalladamente en qué consiste la teoría creacionista, Huidobro dibuja un gráfico que reduce a elementos geométricos el proceso de creación del poema. Escribe Bachelard: "Tornar geométrica la representación, vale decir dibujar los fenómenos y ordenar en serie los acontecimientos decisivos de una experiencia, he ahí la primera tarea en la que se funda el espíritu científico". "Como se verá a continuación, el esquema de Huidobro guarda una gran similitud con los dibujos que se realizan para ilustrar el funcionamiento básico de una máquina.

Todas las máquinas tienen una entrada, mediante la cual reciben energía de la Naturaleza o mundo objetivo (aire, carbón, petróleo, agua, uranio); poseen un mecanismo de transformación y modificación, y una salida bajo la forma de energía mecánica. Dice Huidobro: "El artista obtiene sus motivos y elementos del mundo objetivo, los transforma y combina, y los devuelve al mundo objetivo bajo la forma de nuevos hechos". He aquí el esquema que ilustra dicha concepción:

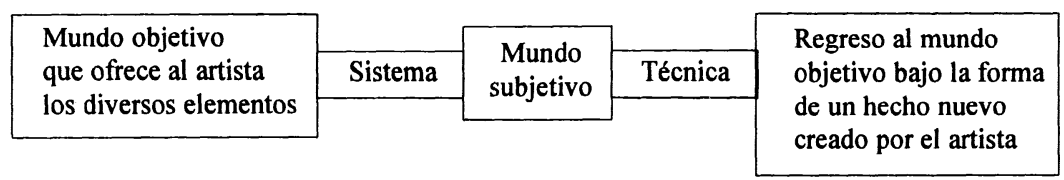

El Sistema es el mecanismo de selección y eliminación de los elementos que la realidad externa pone a disposición del poeta. A través de este conducto, es alimentado el Yo o interioridad del sujeto. En este punto interviene la Técnica, que son los medios de expresión que emplea el poeta para devolver esos elementos desde el Yo al mundo exterior, transformados en fenómenos inéditos. La máquina de crear ha producido el artefacto verbal.

La relación entre la producción de máquinas y la producción de obras de arte es clara en el pensamiento huidobriano. Cuando el poeta ejerce lo que él denomina con precisión su "teoría científica", es decir, su estética, analiza las tres fases bajo las cuales el arte se ha presentado o puede presentarse en su desarrollo: 1. Arte inferior al medio (reproductivo); 2. Arte en consonancia con el medio (de adaptación); y 3. Arte superior al medio (obras

\footnotetext{
${ }^{3}$ Obras completas I, 718-722.

${ }^{4}$ Bachelard 7.
} 
creacionistas). Pues bien, en su novela La próxima hay un momento en que el protagonista las emprende contra los detractores del maquinismo y los acusa de ser "inferiores al medio". La ecuación queda establecida: tanto las obras de arte creacionistas como las máquinas pertenecen a la etapa de creaciones "superiores al medio".

En este contexto es donde surge la oposición Natural / Artificial. Natural es la realidad externa, el mundo de los seres biológicos, de la flora y del reino mineral. La tarea consiste en distanciarse de esos entes no creados por el hombre, e inventar realidades autónomas; mundos y seres artificiales: "En todas las creaciones humanas-dice Huidobro- se ha producido una selección artificial exactamente paralela a la selección natural. Uno encuentra esto tanto en la obra de arte como en la mecánica y en cada una de las producciones humanas" (722). ${ }^{5}$

Estamos aquí, ¿qué duda cabe?, frente a otra versión del motivo del gólem, evidente en Borges, pero no tan evidente en Huidobro. Recordemos que, en términos amplios, el tema se caracteriza por la creación de seres artificiales, a imagen y semejanza de los seres naturales. ${ }^{6}$ En este punto pareceríamos estar cayendo en una contradicción mayúscula, porque el fundamento mismo del creacionismo es negarse a crear nada a imagen y semejanza de los seres naturales. Sin embargo, las siguientes palabras de uno de los personajes de $L a$ próxíma no pueden ser más explícitas: "Dios creó al hombre a su imagen y semejanza, el hombre a su vez ha creado la máquina a su imagen y semejanza" (315). ${ }^{7}$

Aunque no lo parezca a primera vista, ésta no es otra forma de mimesis como reflejo. Lo que sucede es que cuando Huidobro habla de la poesía, aparece una nueva variante del motivo del gólem, que surge, de manera paradójica, justamente de ese rechazo de Huidobro a copiar la Naturaleza: "No se trata de imitar la Naturaleza, sino de hacer como ella; no imitar sus exteriorizaciones sino su poder exteriorizador" (720). Aunque el arte de Huidobro se niega a ser mimético o "reproductivo", no tiene más remedio que obtener sus elementos de la realidad externa; pero sólo para devolverlos a esa misma realidad bajo la forma de hechos nuevos, según hemos visto. Porque como planteaba en el manifiesto "Non serviam": "No he de ser tu esclavo, madre Natura; seré tu amo. Te servirás de mí; está bien. No quiero ni puedo evitarlo; pero yo también me serviré de ti. Yo tendré mis árboles que no serán como los tuyos, tendré mis montañas, tendré mis ríos y mis mares, tendré mi cielo y

\footnotetext{
${ }^{5}$ La vocación de Neruda, en cambio, está con la naturaleza. Por ejemplo, su poema "Walking around" revela una angustiosa hostilidad hacia los productos artificiales: "Sólo quiero no ver establecimientos ni jardines, / ni mercaderías, ni anteojos ni ascensores", Residencia en la tierra, edición de Hernán Loyola (Madrid: Cátedra, 1987) 219-221.

"Véase Oscar Hahn, "Gólem y vanidad en dos textos de Borges", Texto sobre texto (México: UNAM, 1984) 75-87.

${ }^{7}$ A propósito de genética artificial, cabe destacar aquí que en esta novela de 1934, Huidobro describe un procedimiento semejante a lo que ahora se conoce con el nombre de "fecundación in vitro": "Adentro de este globo hay un óvulo femenino. Yo puedo fecundarlo mecánicamente con el esperma de cualquier hombre y dar vida a otro hombre. Sólo necesito darle una temperatura especial y alimentarlo de sangre durante nueve meses", dice. Pero agrega en seguida: "Se acabó la molestia del embarazo, se acabaron los dolores del parto". En vista de que el óvulo fecundado no sería devuelto al vientre materno y se desarrollaría fuera de éste, la criatura resultante debería ser considerada un tipo de gólem (300).
} 
mis estrellas" (715). En suma, el poeta creacionista no reproduce fisiognómicamente los objetos y seres de la Naturaleza, pero sí sus leyes y su funcionamiento, de un modo parecido a esas invenciones que antes pertenecieron el campo de la mecánica y ahora corresponden al de la cibernética.

Que los primeros en practicar el culto a las máquinas fueron los futuristas, es ya un lugar común en la historia de la cultura, como lo es también la célebre frase de Marinetti sobre la superioridad estética del automóvil de carrera. Menos conocida es la declaración de Umberto Boccioni, que en su "Manifiesto Técnico sobre la escultura futurista" dice: "No debemos olvidar que el tic-tac y las manecillas del reloj, el entrar y salir de un pistón en un cilindro, dos ruedas dentadas abriéndose y cerrándose, junto a la continua aparición y desaparición de sus cuadrados dientes de acero; la furia del volante de un motor o de la turbina de una hélice, son todos elementos plásticos y pictóricos que las esculturas de los futuristas deben tomar en cuenta. Una válvula al abrirse y cerrarse crea un ritmo igual de bello, pero infinitamente más nuevo, que el pestañear de los párpados de un animal". 8

Huidobro adopta una perspectiva diferente. En su artículo "Maquinismo y futurismo" afirma que los futuristas no aportaron nada al arte nuevo, excepto "algo de ruido y mucha confusión". Una mirada somera a los textos futuristas - dice- comprueba que se rigen por la misma estética obsoleta que ellos proclaman haber superado. Huidobro sostiene que los futuristas pueblan sus poemas con máquinas, con el único propósito de producir una ilusión de modernidad, y los acusa de haber fundado toda una mitología de la máquina, tan repudiable como la mitología griega que solía plagar a la poesía anterior. "Esto no quiere decir que no debamos usar términos del maquinismo actual", aclara Huidobro. "Esto quiere decir que no debiéramos abusar de ellos y, sobre todo, creernos modernos por otra razón que por la base fundamental de nuestra poesía" (7442-44).

Lo que Huidobro rechaza es el empleo de una nomenclatura o retórica maquinista como elemento externo, meramente decorativo. Porque para él lo que verdaderamente importa es el funcionamiento interno del poema y su adscripción a leyes científicas. Es su carácter de objeto científico agregado a la realidad, lo que lo hace análogo a las máquinas. Dice en La próxima: "El hombre empezó por conquistar los tres reinos de la naturaleza: el reino mineral, el reino vegetal, el reino animal. Luego el hombre creó un nuevo reino, el reino mecánico, el reino que él agregó a la naturaleza" (306). Resulta claro entonces por qué Huidobro cita y suscribe con entusiasmo la afirmación de Saint-Pol Roux de que la poesía es "ciencia en sí, ciencia de las ciencias, capaz de bastarse a sí misma, en posesión de reglas caprichosas, que se diferenciarán de un poeta a otro" (731).

Pero eventualmente el culto a la ciencia y a la tecnología termina transformándose en miedo a su poder destructor. "El hombre ha poblado el mundo de sus monstruos y estos monstruos tienen que producir en él un trastorno hasta que no los haya asimilado totalmente" (306), advierte Huidobro. A este respecto vale la pena traer a colación las siguientes palabras del crítico australiano Robert Hughes: "De ninguna manera - dice Hughestodos los artistas europeos anteriores a la Primera Guerra Mundial compartieron el optimismo acerca de las máquinas, al que se aferraban los futuristas. Algunos lo vieron

\footnotetext{
${ }^{8}$ Umberto Boccioni, "Technical Manifesto of Futurist Sculpture" (1912), en Herschel B. Chipp, Theories of Modern Art (Berkeley, CA: University of California Press) 303.
} 
como algo amenazante y deshumanizador. La idea de que las creaciones del hombre se pudieran levantar contra él y eventualmente destruirlo, fue uno de los mitos fundamentales generados por la Revolución Industrial, mito al que Mary Shelley le dio memorable forma temprana en la novela Frankenstein". 9 Y líneas más adelante, al comentar la escultura The Rock Drill, de Jacob Epstein, que es una especie de gólem o autómata hecho de bronce, Hughes cita las siguientes palabras del propio Epstein acerca de su obra: "Ésta es la siniestra figura armada de hoy y de mañana. Nada humano, sólo el terrible monstruo Frankenstein en el que nos hemos convertido". Como es palmario, el mensaje sigue teniendo plena actualidad. Que la ciencia y la tecnología, después de lanzarnos al futuro, puedan devolvernos violentamente a la edad de las cavernas o depositarnos en las puertas mismas del Apocalipsis son angustias generalizadas de la era nuclear. ${ }^{10} \mathrm{~A}$ inquietudes semejantes dedica Huidobro un libro entero. Es la ya citada novela La próxima, que desde el paradojal subtítulo revela su vocación profética: "Historia que pasó en poco tiempo más"."

Un grupo de pioneros liderados por el millionario Alfredo Roc, a quien apodan "el apocalíptico Roc", se marcha a Angola con el propósito de establecer una colonia, que es también una suerte de Utopía, para salvarse de la inminente destrucción de Europa. El principio del fin es la aniquilación de toda la población de París, por inhalación de un gas que produce la muerte por petrificación de la víctima, pero que deja intactas las cosas materiales. Una tras otra van cayendo las principales ciudades de Europa Occidental y de Europa del Este, y poco después, el continente americano. Al final sólo quedan en pie Angola y los montes Urales, lugar en el que se ha refugiado la población rusa. ${ }^{12}$

En medio de este cuadro apocalíptico, Roc y sus amigos entablan un apasionado debate sobre el futuro de las máquinas. En vista de que Angola se ha convertido en el refugio de sobrevivientes, se trata de determinar qué cosas vale la pena salvar de la catástrofe para construir un mundo nuevo. El debate es precedido por un sueño visionario del protagonista, en el que ve parejas de máquinas embarcándose en el Arca bíblica: "Iban dos hermanos aviones, dos magníficos automóviles, dos locomotoras, dos telescopios a pasos de jirafa, dos microscopios lentos, dos gramófonos chillones, dos sabias linotipias,

\footnotetext{
9 Robert Hughes, "The Mechanical Paradise", en The Shock of the New (New York: Alfred A. Knopf, 1981) 48.

${ }^{10}$ En una entrevista a Huidobro publicada por la revista Zig-Zag de Santiago (26 de septiembre de 1946), Jorge Onfray Barros le pregunta si el miedo a la bomba atómica puede traer la paz y acabar definitivamente con las guerras. Huidobro responde: "No. Lo mismo se dijo hace años a propósito de los gases asfixiantes". Y agrega poco después: "Es lamentable que la utilización de la energía atómica haya empezado en el plano bélico. Es una mancha en el destino de la humanidad que nadie podrá borrar".

"La primera publicación de esta novela es de Ediciones Walton, Santiago, 1934.

${ }_{12}$ De acuerdo con la ideología de La próxima, el comunismo soviético era la única y la última esperanza de la humanidad: "Proletarios del mundo, uníos. Murió el capitalismo. Murió como Sansón aplastando bajo sus escombros a toda la tierra, amigos y enemigos. Murió la burguesía esclavizadora. Proletarios, los pocos que quedáis por el mundo, uníos para empezar la reconstrucción del mundo" (295). Esto decía en 1934. En 1947 Huidobro publica un virulento ataque contra la Revolución Rusa, con el título de “¿Por qué soy anticomunista?” (Revista Estanquero, Santiago de Chile, abril de 1947).
} 
dos aparatos como de radio o de telégrafo, dos teléfonos, dos arcos voltaicos, y más lejos de mí, otra serie de parejas que se perdían de mi vista" (305). Nótese cómo los seres naturales del Arca de Noé han sido reemplazados por seres artificiales en esta Arca onírica.

El centro del debate que hay en La próxima lo ocupa el enfrentamiento entre maquinismo y antimaquinismo; entre los que profesan una nueva fe: "Creo en la máquina, pero sin misticismo; creo en ella como en la libertadora de mi servidumbre", y los que preguntan angustiados: "Y ¿para qué sirven esos inventos? ¿Cuánta parte tienen ellos en este delirio de hecatombe?" (293). Otro de los sobrevivientes sostiene que todas las civilizaciones llegan fatalmente a un punto de autodestrucción, y que "por autodestrucción se inventan las máquinas".

Paralelamente, el debate es una querella entre lo natural y lo artificial: "La naturaleza no entorpece, la naturaleza ayuda al espíritu"; "la vida se ha puesto artificial a causa del maquinismo" (305), dice uno de los personajes. Y su interlocutor responde: "Hay mucho más espíritu en esos monstruos creados por el hombre que en esos animales ajenos al espíritu del hombre" (305). A lo que el primero replica:

La naturaleza ha sido siempre engañada por el hombre, pero ella siempre se ha vengado del hombre. Podéis creerme, los árboles se cuchichean preparando la monstruosa venganza en que ha de caer el hombre (315).

Sea el corolario del instinto autodestructivo del ser humano, como en Altazor, sea el resultado de una venganza de la naturaleza, como en Temblor de cielo, para Huidobro la destrucción del planeta es una tragedia inevitable; pero al mismo tiempo es un mal necesario. El mundo obsoleto, que a duras penas se sostiene sobre estructuras envejecidas, carga consigo el germen de su propia destrucción. Su aniquilamiento es el precio que la humanidad debe pagar para que de sus cenizas nazca el cosmos inaugural: "Para crear un mundo nuevo, hay que empezar todo de nuevo", dice Huidobro (294). El Capítulo XII de La próxima es todo un himno fúnebre, muy a la manera de los cantos de Zarathustra, destinado a celebrar con saña y regocijo la muerte de la Tierra. Vale la pena transcribirlo, aunque sea parcialmente:

No quedará piedra sobre piedra. No quedará hoja en los árboles, ni fruto vivo. Serás el nido de las aves de rapiña. El olor a cadáver subirá como un vaho hasta la luna. Habría sido mejor no haber nacido nunca. Habría sido mejor que la Tierra fuera una bola solitaria o no hubiera salido jamás del seno de su nebulosa. Ser o no ser; he ahí el problema. Serás una bola desierta. Crujirás como una carreta en el camino de tu eclipse. Te dolerán los huesos envejecidos en el invierno interminable. Los otros astros se reirán de ti. Te escupirán al pasar. Te lanzarán piedras y migas de pan. Acaso alguno te arroje una moneda con olor a otros mendigos. Los cometas al cruzarte en su camino enrrollarán su cabellera para librarla de tus piojos. Al oír tus pasos en el infinito todas las estrellas se cubrirán los ojos y huirán de tu contagio. Leprosa. Putrefacta. Cementerio ambulante. Pútrida, con tus océanos de pus. Barco fantasma relleno de esqueletos con tu bandera de andrajos flotando en el aire pestilente (291).

Huidobro vaticina que al final de la historia, el ser humano habrá subyugado a la naturaleza con el instrumento de la razón, así como en el principio la dominó mediante su 
instinto. Enriquecido por los siglos y poseedor de todos los secretos, el hombre emprenderá un viaje circular a los orígenes; una vuelta en espiral al punto de partida, para recomenzar él mismo, con sus propias manos, la fundación del orbe. "Será el período de la creación artificial después del período de la creación natural", dice el poeta. "Y después será el fin del mundo" (309). En el pensamiento de Huidobro, aunque finjan ir hacia el Génesis, todos los caminos conducen al Apocalipsis. 